\title{
O DESIGN DE EMBALAGENS E A COMPLEXIDADE DA DESTINAÇÃO DE SEUS RESÍDUOS NOS SUPERMERCADOS - EXPERIÊNCIAS PRÁTICAS
}

\author{
Dulce de Meira Albach \\ UFPR - Universidade Federal do Paraná \\ dulce.albach@ufpr.br \\ Dalton Luiz Razera \\ UFPR - Universidade Federal do Paraná \\ daltonrazera@ufpr.br
}

\begin{abstract}
Resumo: Este estudo teve como principal objetivo pesquisar iniciativas de gerenciamento do impacto ambiental de resíduos de embalagens de produtos expostos e comercializados em supermercados. Por meio de revisão bibliográfica em artigos científicos e literatura específica, foram selecionadas experiências concretas em distintas realidades de mercado, envolvendo implicações legais, econômicas, ambientais e sociais. $O$ excesso de variáveis e suas influências em cada contexto, denotam a complexidade em se estabelecer critérios e/ou normas globais. No entanto, estima-se que um ponto comum para a busca por melhores resultados para a sustentabilidade ambiental, quanto as referidas embalagens, se caracteriza pelo planejamento de ações conjuntas entre os designers, os produtores, os pontos de venda (supermercados) e os consumidores, garantindo uma responsabilidade compartilhada.
\end{abstract}

Palavras-chave: design de embalagem, supermercado, resíduo sólido.

Abstract: The main objective of this study is to search management initiatives of the environmental impact of packaging waste of products that are exhibited and sold in supermarkets. Through a bibliographical revision in scientific articles and specific literature, real life experiences were selected in different markets realities involving legal, economics, environmental and social implications. The excess of variables and their influences in each context, denote the complexity in establishing global criteria and/or standards. However, it is estimated that a common point to the search for better results for the environmental sustainability, as regards the said packaging, is characterized by planning joint actions among designers, producers, retail sector (supermarkets) and consumers, ensuring a shared responsibility.

Keywords: packaging design, supermarket, solid waste. 


\section{INTRODUÇÃO}

A intensificação da geração de resíduos sólidos, caracterizados por embalagens descartadas, é um fenômeno que se destaca nas discussões sobre sustentabilidade em função dos impactos ambientais gerados. A composição média destes resíduos sólidos no país atinge volumes desproporcionais à capacidade de um adequado gerenciamento de descarte e disposição final. Este fato está relacionado com a concentração da população brasileira em áreas urbanas, que de acordo com o IBGE (2010) corresponde a $85 \%$ do total de habitantes. Esta concentração se deu de forma acelerada nos últimos cinquenta anos, e não foi acompanhada por uma capacidade efetiva de gestão de infraestrutura e de serviços (MENEGAT et al. 2004, p. 36).

Neste contexto, com a evolução do comércio e da sociedade de consumo, as embalagens foram se tornando cada vez mais importantes, principalmente após o surgimento dos estabelecimentos de venda a varejo, chamados de supermercados ${ }^{1}$. Este sistema de venda, denominado de "autosserviço", impulsionou uma revisão do design das embalagens, principalmente em relação às suas funções, transformando-as em ícone da cultura de massa. Para a embalagem foram atribuídas as funções de: conter os produtos (seja em estado sólido, líquido ou gasoso), proteger (ex.: ser hermética e impedir o contato externo com água, umidade, insetos, etc.), identificar seu conteúdo, expor o produto, comunicar (servir de suporte de comunicação entre o produtor e o consumidor), facilitar o transporte e autovender o produto (melhorar vendas), dentro de um cenário cada vez mais competitivo (MESTRINER, 2001, p.17; SANTOS e PEREIRA, 1998, p. 761).

Identificando o ambiente supermercado como um local de grande concentração de embalagens, e, portanto, diretamente envolvido com a geração dos resíduos das mesmas, este estudo pretendeu investigar iniciativas de gerenciamento de resíduos sólidos no referido local e em diferentes países. O intuito foi buscar reconhecer soluções que proporcionem um planejamento ambientalmente mais adequado e, consequentemente, promovam a minimização do grave cenário de poluição que o contexto evidencia. Este conteúdo está relacionado à parte da pesquisa de tese de doutorado em andamento que versa sobre gestão de resíduos e sistemas inovadores para embalagens no setor de autosserviço. Baseou-se, principalmente, na seleção de artigos científicos, em bases de periódicos. Os conteúdos abordados foram relacionados com referências bibliográficas de autores com reconhecimento no assunto e, também, uma associação com as referências apresentadas por Albach (2007). Dentre os exemplos levantados na pesquisa, destaca-se neste artigo a forma de destinação de resíduos de embalagens e as normas regulatórias para a comercialização de produtos embalados adotadas nos seguintes países: Alemanha, Brasil, Canadá, Espanha e Inglaterra. O material consultado apontou para as complexidades que o tema envolve associadas às particularidades de cada contexto.

\section{CLASSIFICAÇÃO E IMPORTÂNCIA DAS EMBALAGENS}

\footnotetext{
1 "O germe dos supermercados, como em tantas áreas no pós-Segunda Guerra Mundial, veio dos Estados Unidos, onde o autosserviço surgiu nos anos 1930, no cenário de precariedade generalizada criado com a crise de 1929. Inicialmente, eliminar balcões e balconistas era um jeito de economizar, convertendo-se nos anos seguintes em maneira mais prática de comprar e vender" (CAVALCANTI e CHAGAS, 2006, p. 133).
} 
Para embasar o reconhecimento das embalagens destinadas ao ambiente supermercado, foi utilizada a classificação do Manual de Planejamento de Embalagens $(1976$, p. 8) que estabelece dois tipos básicos: embalagens de transporte e embalagens de consumo, independente do tipo de material em que são fabricadas. As embalagens de transporte embalam as de consumo e servem basicamente para facilitar a estocagem e o transporte. As embalagens de consumo podem ser classificadas em: display - utilizadas para exposição do produto em locais de venda e de uso - utilizadas durante o consumo do produto. O Quadro 1 apresenta alguns exemplos de embalagens conforme esta classificação. Além disto, as embalagens de consumo também podem ser classificadas quanto ao número de unidades acondicionadas: unitárias ou individual, quando apenas um produto é embalado e de conjunto ou coletiva, quando embala mais de um produto ou mais de uma embalagem individual, facilitando o uso e a distribuição.

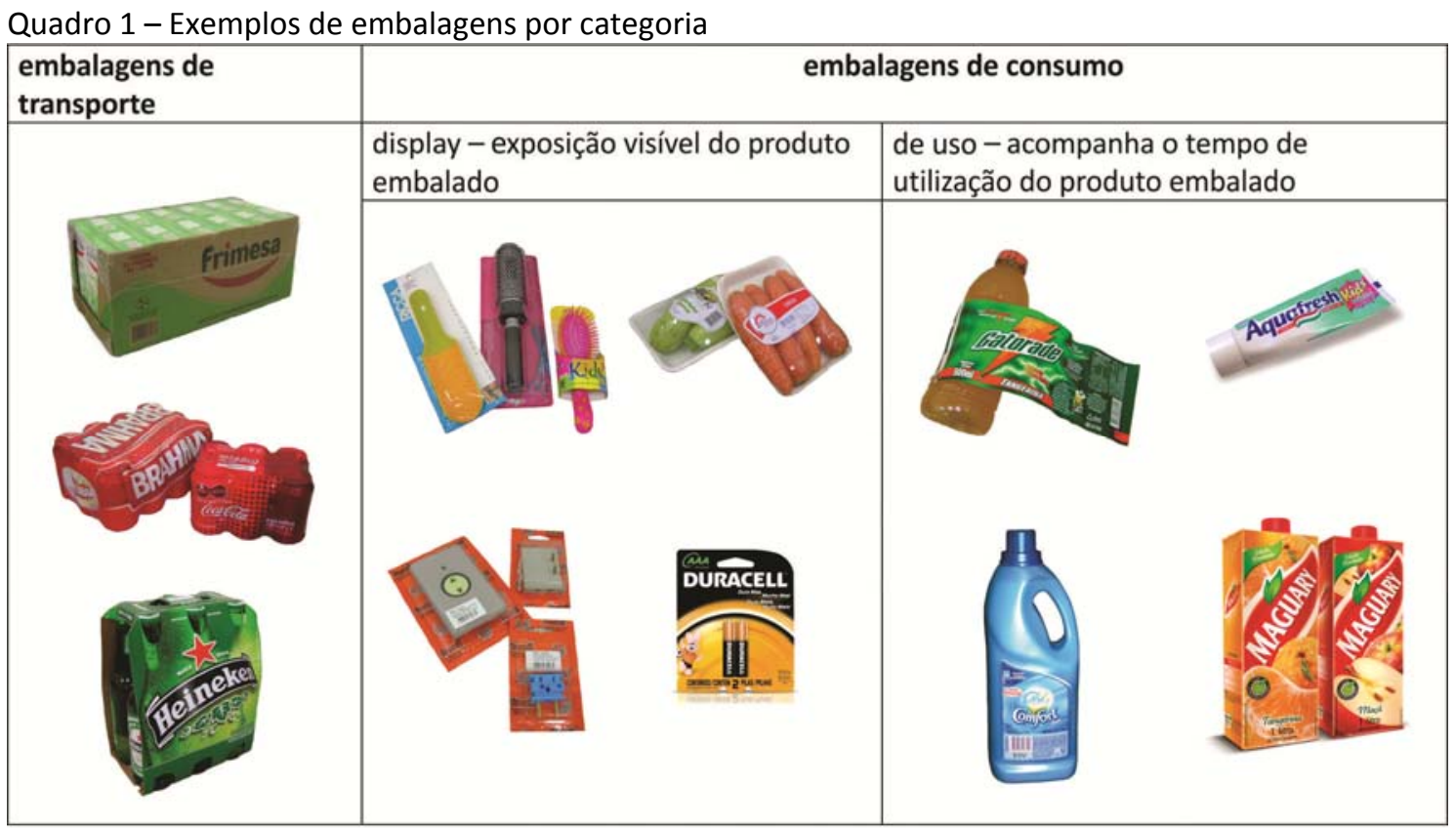

Fonte: Elaborado pelos autores com base no Manual de Planejamento de Embalagens (1976).

Neste contexto e segundo Hine ${ }^{2}$ (1995 apud Kniazeva e Belk, 2012), em média cada consumidor entra em contato com cerca de 11.000 embalagens em um período de 30 minutos de circulação no supermercado. Estas além de proteger os produtos contidos, também são importantes veículos de comunicação. Mestriner (2001, p. 3 e 17) também destaca que as embalagens representam significativas estratégias de comercialização que desenvolvem o setor.

A ABRE - Associação Brasileira de Embalagens (2013) relata que mundialmente esta indústria representa dentre $1 \%$ e $2,5 \%$ do PIB de cada país, sendo que no Brasil movimenta atualmente $\mathrm{R} \$ 47$ bilhões e gera mais de 200 mil postos de emprego diretos e formais. Associa-se ao fator econômico o volume e a visibilidade na produção industrial, pois as embalagens têm forma definida e marcas dos produtos agregadas.

Ressaltando ainda a importância do setor de embalagens, Cavalcanti e Chagas (2006, p. 15) afirmam que a embalagem é o item mais fabricado no mundo e apontam

2 HINE, T. The total package: the secret history and hidden meanings of boxes, bottles, cans, and other persuasive containers. Boston: Back Bay Press, 1995. 
que das vinte maiores empresas de embalagens mundiais, dezoito estão estabelecidas no Brasil, atuando em diferentes setores, como: indústria de alimentos, perfumaria, farmacêutica, higiene e limpeza.

Estes dados evidenciam a vasta oportunidade de atuação dos designers neste segmento, no que tange, também, ao planejamento da adequada destinação dos resíduos sólidos gerados.

\section{POLÍTICAS AMBIENTAIS}

Em análise à importância das embalagens é destacável o fato de que a composição média nacional de resíduos sólidos secos é de 31,9\%. E, embora o principal componente do lixo urbano seja o resíduo orgânico, com composição média nacional de $51,4 \%$, as embalagens de uso doméstico se destacam pela grande importância que representam dentro do contexto econômico (MMA, 2012). Destacamse também pelo volume e visibilidade (CEMPRE, 2000, p.9).

Quanto à destinação dos resíduos, a legislação Brasileira, que até o início dos anos 1970 tendia a responsabilizar os governantes locais pelo impacto ambiental dos resíduos sólidos, reorientou suas concepções. A legislação mais recente visa responsabilizar os fabricantes, direta ou indiretamente, pelo impacto de seus produtos no meio ambiente, seja por meio de leis dirigidas à reciclagem ou por meio de proibições de disposição em aterros sanitários (GONÇALVES-DIAS, 2006).

No ano de 2010, depois de vinte anos de tramitação no Congresso Nacional, foi aprovada, por meio da Lei no 12.305/10 a Política Nacional de Resíduos Sólidos. Entre outros aspectos, destaca-se a denominada "responsabilidade compartilhada", pela qual os fabricantes, importadores, distribuidores, comerciantes, consumidores e titulares dos serviços públicos de limpeza urbana e de manejo de resíduos sólidos são responsáveis pelo ciclo de vida dos produtos. Esta política prevê que o poder público deve apresentar planos para o manejo correto de materiais e às empresas compete o recolhimento dos produtos após o uso. Para a sociedade cabe participar dos programas de coleta seletiva e incorporar mudanças de hábitos para reduzir o consumo e a consequente geração de resíduos (BRASIL, 2010).

Este cenário amplia o espaço para atuação dos designers, que indiscutivelmente podem contribuir de forma efetiva, em diferentes aspectos para que as metas preconizadas sejam atingidas. Segundo o MMA (2012) estas metas se caracterizam como desafios importantes, tanto para o poder público quanto para o setor privado do país. Uma das confirmações quanto a isto pode ser observada nos dados do IBGE (2008) que expõem que $60,5 \%$ dos municípios brasileiros descartam lixo de forma inadequada e 6,4 milhões de toneladas sequer são coletadas, sendo despejadas irregularmente ao longo de vias urbanas, em córregos, praias, etc..

Neste sentido, foi criada também a série de normas ISO 14000, com representação legal no Brasil por meio da ABNT - Associação Brasileira de Normas Técnicas, cujo objetivo é o de orientar a elaboração de Políticas Ambientais, com vistas a uma aceitação internacional. Estas normas foram divididas em dois grandes grupos: 1) orientadas para processos: destinada às organizações e 2) orientadas para produtos: se refere a impactos ambientais de produtos e serviços sobre o seu ciclo de vida, rotulagem e declarações ambientais. Um dos conceitos norteadores da criação das normas ISO é a aplicação de incentivos ao invés de políticas repreensivas e vale ressaltar que não substituem a legislação vigente de cada país. 
$\mathrm{Na}$ discussão quanto à responsabilidade no setor de embalagens no Brasil, Santos et al. (2004) analisam o sistema de coleta seletiva como um primeiro passo para viabilizar as atividades recicladoras. Os autores sugerem a criação de taxas para embalagens não recicláveis; a imposição obrigatória do uso de reciclado em alguns setores produtivos e o incentivo ao uso de artigos exclusivos de material reciclado. Outra sugestão é o uso de embalagens com menor número de resinas plásticas diferentes e o design de projetos que facilitem a separação de componentes, evitando, na medida do possível, as embalagens multicamadas, excesso de adesivos, aditivos e ou rótulos.

Por outro lado, Stewart (2010, p. 133) propõe uma reflexão sobre a importância de haver um contrabalanceamento entre a escala do problema do descarte de embalagens com os benefícios trazidos por estas, antes do descarte, em termos de questões ambientais, como: prevenir a perda de produtos perecíveis, havendo menos desperdício de produtos; ou protegendo os produtos no transporte, preservando a energia investida na produção. O autor destaque que "Quando os produtos são danificados, o custo ambiental para repô-los pode ser considerável. A energia utilizada na produção e no transporte para sua reposição será duplicada" (STEWART, 2010, p. 134).

Ainda observando as variáveis que embasam o setor em análise, Jayaraman et al. (2003) destacam o número crescente de empresas interessadas em minimizar os impactos ambientais de seus produtos e serviços, com interesse em terem atitudes pró-ativas mais adequadas do que uma abordagem "fim do tubo" ${ }^{3}$ (como, por exemplo, coleta seletiva e reciclagem). Os autores afirmam que há uma grande pressão das partes corporativas interessadas, comunidade, funcionários, governo e clientes para que as organizações sejam ambientalmente conscientes.

Neste sentido, e para aprimorar os processos de destinação de resíduos de embalagens, diversos países vêm propondo modelos para gestão de impactos ambientais.

\section{PROPOSTAS DE GERENCIAMENTO DE RESÍDUOS DE EMBALAGENS}

No processo de levantamento de dados nas referências pesquisadas, foram selecionados exemplos de situações distintas, visualizando a amplitude que a destinação de resíduos de embalagens denota, bem como, as implicações de gerenciamento em cada contexto.

\section{A iniciativa da Alemanha}

A influência da Alemanha nas discussões sobre legislação quanto à embalagem e seu descarte, segundo Stewart (2010), é de grande relevância. Um momento importante e de referência naquele país foi à introdução de programas para transporte e venda de embalagens, no início da década de 90 , com destaque para a máxima "o poluidor paga". O programa estabelecia um sistema de ciclo fechado, no qual, a embalagem era reusada ou reciclada, não se admitindo a destinação para aterros sanitários ou incineração. Neste caso, "os fabricantes e distribuidores eram responsáveis pela recuperação, reuso ou reciclagem de toda a embalagem" e, no caso de embalagens de venda, os consumidores poderiam devolvê-las aos varejistas ou

\footnotetext{
${ }^{3}$ Fim do Tubo (do termo em inglês "end-of-pipe"), segundo Kazazian (2005), se refere a realização de controle com as questões ambientais, apenas no final do processo.
} 
descartá-las no ponto de venda e estes se responsabilizariam pela destinação. Em relação a este regulamento associou-se a especificação de peso mínimo que a embalagem deve ter para proteger o produto, bem como a definição por materiais compatíveis com o meio ambiente. Especificamente para embalagens de venda, foi estabelecida uma empresa privada, a Duales System Deutchland (DSD) como responsável por coletar, selecionar e destinar as embalagens descartadas. Esta criou um símbolo (Figura 1) denominado "Grüne Punkt" (Ponto Verde) e os embaladores tinham que negociar com seus fornecedores o uso deste, associado a acordos de taxas aplicáveis para cobrir a coleta e a seleção das embalagens.

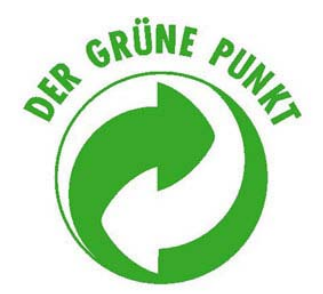

Figura 1 - Grüne Punkt (Ponto Verde) Fonte: Der Grüne Punkt (2013).

Num primeiro momento, Stewart (2010, p. 152) esclarece que a Comunidade Europeia foi hostil a estes procedimentos. No entanto, a maioria das empresas acabou optando por aderir à DSD, fato este que se espalhou para a Inglaterra e posteriormente a outros países europeus, sendo que o "Ponto Verde" acabou se tornando, diante da interpretação dos consumidores, como um símbolo europeu de reciclagem.

\section{Exigências legais no Canadá}

Ferrara e Plourbe (2004) apresentam uma análise em relação aos efeitos provocados, desde 1985, com a lei Canadense que exige que um volume mínimo de $30 \%$ de bebidas carbonatadas deve ser vendido em embalagens de vidro retornáveis, considerando que esta atitude provoca mudanças positivas nas questões de proteção ambiental referentes ao assunto. Estas bebidas são vendidas em três tipos de embalagens: garrafa de vidro (retornável e não retornável), garrafas de plástico PET e latas de alumínio ou bimetal, promovendo diferentes tipos de impactos no fluxo de seus resíduos sólidos. Visando encorajar o retorno de embalagens adquiridas pelos consumidores, os autores destacam outra medida governamental, iniciada nos EUA, que se refere ao depósito e reembolso do valor pago na compra e no retorno da embalagem, respectivamente, além de proibir a venda de bebidas em lata. No Canadá este critério começou a valer para todos os tipos de refrigerantes em algumas cidades.

Os autores apresentam uma proposta com relação a programas do tipo "pague pelo que descarta" (livre tradução do termo em inglês "pay-as-you-throw") que podem significar uma redução considerável na quantidade dos resíduos gerados, porém, não são necessariamente capazes de induzir os consumidores a utilizar embalagens retornáveis.

\section{Impacto ambiental na Espanha}

Pela Espanha ser um grande produtor de leite e este ser um importante ingrediente da dieta alimentar daquele país, existe uma variedade de embalagens específicas no mercado. Uma análise destas embalagens foi elaborada por Meneses et 
al. (2012) considerando a sua disposição em aterro, incineração ou reciclagem. Para aterro se considerou a infraestrutura de despejo, o uso da terra, o efeito dos resíduos depositados (lixiviados) e as emissões no solo, ar e nas águas subterrâneas. Para incineração: a infraestrutura da planta, o processo da incineração propriamente dito, a eletricidade gerada e a disposição das cinzas em aterro. E, para reciclagem: a infraestrutura da planta, os processos de separação e reciclagem, e os produtos obtidos com o resíduo regenerado.

Concluiu-se que os diferentes tipos de disposição não dependem apenas da operação do tratamento, mas também da possibilidade de redução de energia. $E$, na avaliação dos indicadores ambientais, analisando o ciclo de vida do leite, desde a produção, embalagem, transporte (para $100 \mathrm{~km}$ - distribuição local) e disposição final da embalagem para a reciclagem, pode-se afirmar que a fase de produção do leite é a que gera maior impacto. Meneses et al. (2012) destacam outros estudos, nos quais a fase agrícola da produção do leite é um elemento crucial e enfatizam que o estudo por eles realizado considera apenas a Espanha e caso o parâmetro fosse a Comunidade Europeia, os resultados seriam diferentes. Observou-se desta forma que a produção do leite mascara os outros impactos ambientais na análise do ciclo de vida. No entanto, estudos mostraram que o impacto para outros tipos de bebidas é diferente. Quando sucos, água e cerveja foram analisados, no geral, o efeito das embalagens é mais importante.

\section{Experiência na Inglaterra}

$\mathrm{Na}$ redução da geração de resíduos na Inglaterra, focado nas formas de transportar e expor os produtos embalados, Dixon-Hardy e Curran (2009) estabelecem um comparativo entre a utilização de pallets de madeira para caixas de papelão (Figura 2), gaiolas de armazenamento (Figura 3), e engradados plásticos (RPC - Reusable plastic container) (Figura 4).

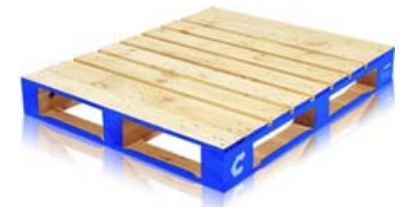

Figura 2 - pallet de madeira Fonte: CHEP, 2013.

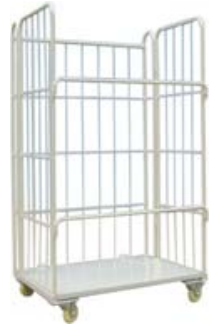

Figura 3 - gaiola de armazenamento Fonte: FOSHAN, 2013.

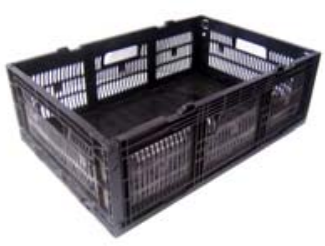

Figura 4 - engradado plástico Fonte: WENCO, 2013.

Segundo os autores, a utilização de pallets de madeira (certificada) se caracteriza por uma base que comportará, geralmente, caixas de papelão ondulado envoltas por um filme plástico de Polietileno da Baixa Densidade (PEBD), pelo processo denominado shrink. Este filme pode apresentar diferentes índices de elasticidade. Quando sua aplicação é manual há um estiramento de $10 \%$ e quando é utilizado processo robotizado, o estiramento pode chegar a $250 \%$, reduzindo a quantidade de filme e, consequentemente, custos. O filme pode ser facilmente removido e é reciclável. As gaiolas de armazenamento são feitas de aço com alta resistência, acabamento anticorrosão e possuem rodízios para auxiliar na função de seu deslocamento. Estas comportam as embalagens ou os próprios produtos a granel, 
conforme seu tipo, não havendo necessidade de utilização de shrink e reduzindo, na maioria das vezes, embalagens secundárias. Os engradados de plástico (RPC), feitos de Polipropileno (PP), em função da ventilação pelas aberturas laterais, são indicados para transportar frutas e vegetais, como também, embalagens de consumo individuais.

A descrição feita por Dixon-Hardy e Curran (2009) de alguns produtos embalados, em termos práticos, possibilitou a elaboração do Quadro 2 que identifica aspectos de desempenho nos três tipos em observação.

Quadro 2 - Aspectos de desempenho entre os tipos de transporte e exposição de produtos

\begin{tabular}{|c|c|c|}
\hline $\begin{array}{l}\text { pallet de madeira para caixas } \\
\text { de papelão }\end{array}$ & gaiola de armazenamento & engradado plástico \\
\hline $\begin{array}{l}\text { - as caixas de papelão são } \\
\text { recicláveis e reutilizáveis } \\
\text { - os tamanhos e formatos } \\
\text { diferentes das embalagens } \\
\text { causa instabilidade na } \\
\text { montagem do pallet } \\
\text { - facilidade de estocagem } \\
\text { - o filme shrink protege da } \\
\text { umidade e é reciclável } \\
\text { - necessidade de utilização de } \\
\text { empilhadeiras para } \\
\text { deslocamento dos pallets }\end{array}$ & $\begin{array}{l}\text { - roladas diretamente do caminhão } \\
\text { para a loja } \\
\text { - exige controle do peso para que } \\
\text { não tombe } \\
\text { - o conteúdo é colocado } \\
\text { diretamente nas prateleiras } \\
\text { - na gaiola vazia podem ser } \\
\text { colocados todos os resíduos de } \\
\text { papelão e plástico e serem } \\
\text { encaminhados para a devida } \\
\text { destinação (ex.: reciclagem) } \\
\text { - não há necessidade de shrink } \\
\text { - não há proteção contra umidade } \\
\text { (conforme a necessidade do } \\
\text { produto) }\end{array}$ & $\begin{array}{l}\text { - facilidade de empilhamento } \\
\text { - facilidade de retirada do } \\
\text { produto e/ou embalagem pelo } \\
\text { consumidor } \\
\text { - não há resíduo de embalagem } \\
\text { secundária } \\
\text { - reutilizável } \\
\text { - necessita de transporte para } \\
\text { retornar ao depósito } \\
\text { - necessita de limpeza (lavagem) } \\
\text { - necessita grande espaço de } \\
\text { depósito (estocagem) para } \\
\text { juntar um determinado } \\
\text { número em períodos }\end{array}$ \\
\hline
\end{tabular}

Fonte: Elaborado pelos autores com base nos dados de Dixon-Hardy e Curran (2009).

Nas três formas abordadas para transporte e exposição de embalagens, observa-se que, no caso dos pallets, quando os shrinks são abertos e as caixas de papelão esvaziadas, ambos são encaminhados para a reciclagem. No caso das gaiolas, não há shrink, no entanto, há resíduos de embalagens que podem ser encaminhados para a reciclagem, com a facilidade que a própria gaiola possibilita o transporte neste retorno. $E$, no caso do engradado plástico, é onde se observa redução da quantidade de material para reciclagem e a evidência de uma proposta voltada para a reutilização.

\section{Proposta de descarte pré-consumo de embalagens no Brasil}

No intuito de promover uma ação prática que contribua com o ciclo de vida de embalagens domésticas, o Sistema de descarte pré-consumo denominado "Caixa Verde ${ }^{4 \prime}$, adaptado de Albach (2007), instalado no Brasil, exemplifica a proposta. Este sistema caracteriza-se pela instalação de containers nos supermercados, nos quais os consumidores podem realizar e conforme sua própria escolha, um descarte antecipado de embalagens adquiridas em que não haja necessidade de serem levadas com o produto. A destinação destas embalagens para a reciclagem é administrada por Cooperativas de Catadores, devidamente cadastradas, possibilitando a redução do volume de embalagens sem destino planejado.

\footnotetext{
${ }^{4}$ Este sistema foi implantado em 2006, no Supermercado Festval Barigui, na cidade de Curitiba - PR, com o nome de "Caixa Ecológico" e em 2008 na rede de supermercados Pão de Açúcar, com o nome de "Caixa Verde". Neste artigo será utilizado o nome "Caixa Verde" devido à ampliação que o sistema tem obtido no referido local. Seu planejamento é resultado da dissertação de mestrado de Albach (2007).
} 
As instalações do Caixa Verde foram iniciadas em 2008, na cidade de São Paulo, nas lojas da Companhia Brasileira de Distribuição (CBD), detentoras das bandeiras de Supermercados Pão de Açúcar e Hipermercados Extra. Posteriormente, o sistema foi estendido para todas as lojas de supermercados e hipermercados da Rede no Brasil.

$\mathrm{Na}$ intenção de uma ação prática, o "Caixa Verde" representa uma parcela de contribuição ao ciclo de vida das embalagens domésticas. Visa atingir os envolvidos para o questionamento de suas atitudes, sua forma de consumir, sua parcela de responsabilidade e, de como a sua conscientização e comprometimento podem interferir em questões ambientais. Não se trata de uma postura de crítica à existência das embalagens, e sim de buscar formas de melhor utilizá-las visando uma organização e gerenciamento da produção e do descarte dos seus resíduos de forma comprometida com a proteção ambiental.

\section{DISCUSSÃO}

Do conteúdo até aqui pesquisado, destaca-se a preocupação com o volume de resíduos gerados por embalagens e as propostas específicas sobre o assunto. Alguns países, como exemplo a Alemanha, têm tradição no assunto enquanto outros buscam seguir exemplos e adequá-los à sua realidade.

Em referência ao caso da imposição da lei canadense para as embalagens de vidro retornáveis, Ferrara e Plourbe (2004) salientam que esta não considera qualquer relutância potencial de varejistas para distribuí-las, pois os supermercados tendem a ter uma política de preços baixos e rápida rotatividade de mercadorias, preferindo, portanto, embalagens não retornáveis. A lei tão pouco considera o resultado de pesquisas que apontam os índices de preferência dos consumidores, que oscila por gostos entre os diferentes tipos de embalagens (vidro, PET e lata). Estes consumidores também declaram entender o fato de que garrafa de vidro retornável utiliza menos energia do que lata de alumínio e garrafa plástica no processo de fabricação. Porém, o estudo também revela que o mesmo não está disposto a pagar mais por isto. Este fato é de extrema relevância, pois para que um sistema como o proposto, de embalagens retornáveis, funcione, o comprometimento do consumidor em todo o processo é fundamental, pois caso contrário, gerará um impacto ambiental negativo ainda maior.

Ou seja, a ação conjunta dos agentes envolvidos é crucial para o sucesso da proposição. Esta é, também, a constatação do caso do sistema de descarte préconsumo de embalagens no Brasil. Neste, observa-se a necessidade de se ampliar o universo atingido para os demais agentes envolvidos no ciclo de vida das embalagens, analisando o momento de sua criação (design), seguido das etapas percorridas, anteriormente ao momento de descarte. Trata-se de se abordar um cenário mais amplo e aprofundado, não limitando a participação apenas do ponto de venda e do consumidor e, consequentemente, com ações que enfoquem uma maior distribuição da responsabilidade nas atitudes/atividades de todos os envolvidos. A análise do perfil do público-alvo direto também é fator de destaque, na medida em que se constatou que os consumidores dos supermercados tem uma participação mais efetiva e simpatizante com a proposta; fato que não ocorre nos hipermercados.

Outro fator de destaque entre os casos pesquisados é a forma de se tratar a logística da embalagem propriamente dita. O universo de tipos de materiais para embalagem é bastante vasto, da mesma forma que o de produtos a serem embalados. A análise do ciclo de vida é um importante aliado no processo de definição da escolha 
do melhor material, bem como, da forma de transporte. Nesta, se levará em conta, entre outros fatores, detalhes sobre o tipo do produto, sua forma de comercialização, envolvendo o perfil do consumidor e o tipo de supermercado onde este consumidor fará sua escolha e compra. A seleção do perfil dos agentes que farão parte do ciclo também é fundamental, na medida em que se evidencia capacidade produtiva, questões tecnológicas, comprometimento e condutas de ação. Detalhes como tamanho da loja, espaço físico para depósito e forma de disposição dos produtos nas prateleiras exercem uma correlação estreita com um adequado projeto da embalagem, ampliando, muitas vezes, as funções da própria embalagem e, consequentemente, gerando economia e benefícios ambientais.

A maioria das discussões e propostas que há algum tempo se restringia à reciclagem, está sendo deslocada para um pensar na redução da embalagem, ou seja, mensurar as premissas de projeto em relação à redução dos gastos do processo produtivo (ex.: de materiais, de energia, de logística, etc.), bem como da redução de resíduos gerados em todas as fases, modificando assim, o tipo de resíduo de embalagem conforme se analisa atualmente na maioria dos casos, no tocante a destinação final.

Dixon-Hardy e Curran (2009) destacam as premissas do Department for Environment Food \& Rural Affairs (DEFRA), órgão do governo britânico responsável por políticas e regulamentações na área de meio ambiente, e que aponta para o programa "Wast Strategy 2000 for England and Wales", segundo o qual, o lixo deve ser tratado prevendo a seguinte hierarquia: $1^{\circ}$ ) reduzir o lixo produzido; $2^{\circ}$ ) reutilizar os produtos que forem possíveis; 3 ㅇ) reciclar o que não pode ser reutilizado e recuperar a energia de resíduos que não podem ser reciclados e 4으) eliminar os resíduos remanescentes em aterro. Este conceito vem de encontro também ao European Packaging and Packaging Waste Directive'94, que promulga a prevenção como o primeiro passo antes de se pensar em reciclagem ou recuperação. Considera a responsabilidade do produtor enquanto agente competente para prever o que vai acontecer com a embalagem no final de seu ciclo de vida, ou seja, que a mesma tenha um projeto desenhado para uma disposição final fácil e com o mínimo de impacto ambiental.

\section{CONSIDERAÇÕES FINAIS}

Apesar do Brasil vir apontando para sinais de preocupação e revisão de atitudes em relação ao assunto, observa-se que o processo é lento no sentido da conscientização e predisposição, na medida em que provoca mudanças, na maioria dos casos, significativas. Apesar da criação de conceituações e/ou leis nacionais, muitas não foram aplicadas ou o são parcialmente. Há uma dificuldade em se ter órgãos fiscalizadores que garantam o cumprimento das mesmas. Por outro lado, muitos municípios brasileiros não conseguiram, até o momento, implantar um sistema de coleta seletiva, ou seja, não há nem a logística mínima para se encadear um possível processo mais próximo de uma adequada destinação, como reciclagem, por exemplo.

No entanto, o desafio para se aliar as forças econômicas com uma produção ambientalmente sustentável e estas às decisões de consumo, é observado em todos os casos pesquisados. A preconização da "responsabilidade compartilhada", chamando a todos os agentes envolvidos para a distribuição de responsabilidades, evidencia-se como uma meta importante, estipulada, inclusive, pelas legislações nacionais mais recentes. 
É notório que no cenário urbano ainda há muito por se fazer em relação à geração de resíduos no planejamento de embalagens, no caso aqui específico, de produtos que são comercializados em supermercados.

\section{REFERÊNCIAS}

ABRE - Associação Brasileira de Embalagens. A embalagem nos dias de hoje. Disponível em: < http://www.abre.org.br/setor/apresentacao-do-setor/a-embalagem/. Acesso em 16 dez. 2013.

ALBACH, Dulce de Meira. Caixa Ecológico: modelo implementado em um supermercado de Curitiba, Paraná, Brasil. Dissertação de mestrado, Centro de Estudos Superiores Positivo, 2007.

BRASIL. Lei no 12.305 de 02 de agosto de 2010. Institui a Política Nacional de Resíduos Sólidos; altera a Lei no 9.605 de 12 de fevereiro de 1998; e dá providências. Diário Oficial da União, Brasília, no 147, p. 3, 02 ago. 2010.

CAVALCANTI, Pedro; CHAGAS, Carmo. História da Embalagem no Brasil. São Paulo: ABRE, 2006.

CEMPRE. Manual de Gerenciamento Integrado do Lixo Municipal. São Paulo: Instituto de Pesquisas Tecnológicas: CEMPRE, 2000.

CHEP. Wooden Pallets. Disponível em: <http://www.chep.com/Pallets/Wooden pallets/>. Acesso em 25 mai. 2013.

DER GRÜNE PUNKT. Duales System Deutschland GmbH (DSD). Disponível em: <http://www.grue_ner-punkt.de/?L=1>. Acesso em 26 mai. 2013.

DIXON-HARDY, Darron W.; CURRAN, Beverley A. Types of packaging waste from secondary sources (supermarkets) - The situation in the UK. Waste Management, Filadélfia, n. 29, p. 1198-1207, 2009.

GONÇALVES-DIAS, Sylmara Lopes Francellino. Há vida após a morte: um (re)pensar estratégico para o fim da vida das embalagens. Gest. Prod., São Carlos, v. 13, n. 3, p. 463-474, set.-dez. 2006.

FERRARA, Ida; PLOURBE, Charles. Refillable versus non-refillable containers: the impacto $f$ regulatory measures on packaging mix and quality choices. Resouces Policy, Filadélfia, n. 29, p. $1-13,2004$.

FOSHAN Huashunxing Arte Metal Products Co., Ltd. Supermarket storage cart cage with wheels HSX-92. Disponível em: <http://display-rack.en.alibaba.com/product/ 54319373121020274501/supermarket_storage_cart_cage_with_wheels_HSX_92.html >. Acesso em 25 mai. 2013.

IBGE - Instituto Brasileiro de Geografia e Estatística. Pesquisa Nacional de Saneamento Básico - 2008. Rio de Janeiro, 2008. 219p. Disponível em: <http://www.ibge.gov.br/ho me/estatistica/populacao/condicaodevida/pnsb2008/PNSB_2008.pdf>. Acesso em 20 mai. 2013. 
JAYARAMAN, Vaidyanathan; PATTERSON, Raymond A.; ROLLAND, Erik. The design of reverse distribution networks: models and solution procedures. European Journal of Operational Research, Filadélfia, n. 150, p. 128 -149, 2003.

KAZAZIAN, Thierry. Haverá a idade das coisas leves: design e desenvolvimento sustentável / organizado por Thierry Kazazian; tradução de Eric Roland René Heneault. São Paulo: Editora Senac São Paulo, 2005.Título original: II y aura l'âge dês choses légères: design et développement durable.

KNIAZEVA, Maria; BELK, Russell W. Supermarkets as libraries of postmodern mythology. Journal of Business Research, Filadelfia, n. 63, p. 748-753, 2010.

Manual para Planejamento de Embalagens. Ministério da Indústria e do Comércio, Secretaria de Tecnologia Industrial, Instituto de Desenho Industrial do Museu de Arte Moderna do Rio de Janeiro. Rio de Janeiro: Atelier de Arte e Editoração MG, 1976.

MENEGAT, Rualdo; ALMEIDA, Gerson. Desenvolvimento Sustentável e Gestão Ambiental nas Cidades: estratégias a partir de Porto Alegre. Organizado por Rualdo Menegat e Gerson Almeida; David Satterwaite et al. Porto Alegre: Editora da UFRGS, 2004.

MENESES, Montse; PASQUALINO, Jorgelina; CASTELLS, Francesc. Environmental assessment of the milk life cicle: The effect of packaging selection and the variability of milk production data. Journal of Environmental Management, Filadélfia, n. 107, p. 76 - 83, 2012.

MESTRINER, Fabio. Design de Embalagem - Curso Básico. São Paulo: Makron Books, 2001.

MMA - Ministério do Meio Ambiente; ICLEI (Governos Locais para a Sustentabilidade) - Brasil. Planos de Gestão de Resíduos Sólidos: Manual de Orientação. Brasília: MMA, 2012.

SANTOS, Amélia S. F.; AGNELLI, José Augusto M.; MANRICH, Sati. Tendências e Desafios da Reciclagem de Embalagens Plásticas. Polímeros, São Carlos, v. 14, n. 5, p. 307-312, 2004.

SANTOS, Maria Cecília Loschiavo dos; PEREIRA, Andréa Franco. As várias vidas dos produtos, materiais e embalagens na cultura material da sociedade de consumo ao homeless. In: CONGRESSO BRASILEIRO DE PESQUISA E DESENVOLVIMENTO EM DESIGN, 3., 1998, Rio de Janeiro. Anais do III Congresso Brasileiro de Pesquisa e Desenvolvimento em Design, Rio de Janeiro: AEND-BR, 1998. p. 0760-0770.

STEWART, Bill. Estratégias de Design para Embalagens / Bill Stewart: tradução da segunda edição americana: Freddy Van Camp. São Paulo: Blucher, 2010. Título original: Packaging Design Strategies.

WENCO S.A.. Plastic box pallets. Disponível em: <http://www.wenco.com.ar/ in/buscarproDucto.php?producto=6186>. Acesso em 25 mai. 2013. 